\title{
Associations between cardiovascular disease, cancer, and very low high-density lipoprotein cholesterol in the REasons for Geographical and Racial Differences in Stroke (REGARDS) study
}

\author{
Peter Penson ${ }^{1}$, D. Leann Long ${ }^{2}$, George Howard², Virginia J. Howard ${ }^{3}$, Steven R. Jones ${ }^{4}$, \\ Seth S. Martin ${ }^{4}$, Dimitri P. Mikhailidis ${ }^{5}$, Paul Muntner ${ }^{3}$, Manfredi Rizzo ${ }^{6,7}$, \\ Daniel J. Rader ${ }^{8}$, Monika M. Safford ${ }^{9}$, Amirhossein Sahebkar ${ }^{10,11}$, Peter P. Toth ${ }^{4,12}$, and \\ Maciej Banach ${ }^{13,14,15}$ *
}

${ }^{1}$ School of Pharmacy and Biomolecular Sciences, Liverpool John Moores University, Liverpool, UK; ${ }^{2}$ Department of Biostatistics, UAB School of Public Health, Birmingham, AL, USA;

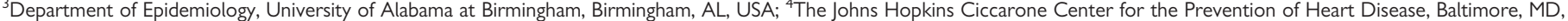

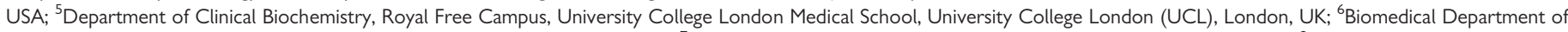
Internal Medicine and Medical Specialties, University of Palermo, Palermo, Italy; ${ }^{7}$ Euro-Mediterranean Institute of Science and Technology, Palermo, Italy; ${ }^{8}$ Department of Medicine,

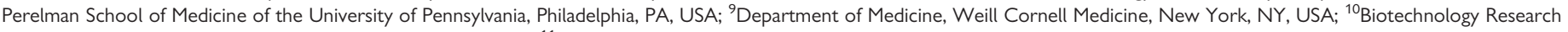
Center, Mashhad University of Medical Sciences, Mashhad, Iran; ${ }^{11}$ Metabolic Research Centre, Royal Perth Hospital, School of Medicine and Pharmacology, University of Western

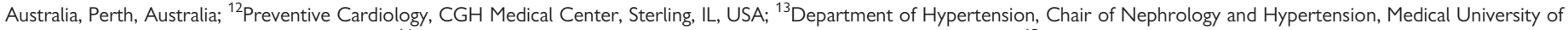

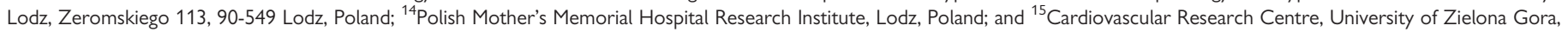
Zielona Gora, Poland

Received 5 June 2018; revised 21 June 2018; editorial decision 29 July 2018; accepted 1 August 2018; online publish-ahead-of-print 3 August 2018

Time for primary review: 2 days

Aims

Relatively little is known about the health outcomes associated with very low plasma concentrations of high-density lipoprotein cholesterol (HDL-C) mainly because of the small numbers of individuals with such extreme values included in clinical trials. We, therefore, investigated the association between low and very low HDL-C concentration at baseline and incident all-cause-mortality, death from malignant disease (i.e. cancer), and with fatal or non-fatal incident coronary heart disease (CHD) in individuals from the Reasons for Geographical And Racial Differences in Stroke (REGARDS) study.

Methods and results
Analysis was based on 21751 participants from the REGARDS study who were free of CHD, other cardiovascular disease, and cancer at baseline and were categorized by baseline HDL-C into $<30 \mathrm{mg} / \mathrm{dL}$ (very low), $30-<40 \mathrm{mg} / \mathrm{dL}$ (low), and $\geq 40 \mathrm{mg} / \mathrm{dL}$ (reference). A series of incremental Cox proportional hazards models were employed to assess the association between the HDL-C categories and outcomes. Statistical analysis was performed using both complete case methods and multiple imputations with chained equations. After adjustment for age, race, and sex, the hazard ratios (HRs) comparing the lowest and highest HDL-C categories were 1.48 [95\% confidence interval (Cl) 1.28-1.73] for all-cause mortality, $1.35(95 \% \mathrm{Cl} 1.03-1.77)$ for cancer-specific mortality and $1.39(95 \% \mathrm{Cl}$ 0.99-1.96) for incident CHD. These associations became non-significant in models adjusting for demographics, cardiovascular risk factors, and treatment for dyslipidaemia. We found evidence for an HDL paradox, whereby low $\mathrm{HDL}(30-<40 \mathrm{mg} / \mathrm{dL})$ was associated with reduced risk of incident CHD in black participants in a fully adjusted complete case model (HR 0.63; $95 \% \mathrm{Cl} 0.46-0.88)$ and after multiple imputation analyses ( $\mathrm{HR} 0.76 ; 95 \% \mathrm{Cl} 0.58-$ 0.98). HDL-C ( $<30 \mathrm{mg} / \mathrm{dL})$ was significantly associated with poorer outcomes in women for all outcomes, especially with respect to cancer mortality (HR 2.31; $95 \% \mathrm{Cl} 1.28-4.16)$ in a fully adjusted complete case model, replicated using multiple imputation (HR 1.81; 95\% Cl 1.03-3.20).

* Corresponding author. Tel: +48 42639 3771; fax: +48 42639 3771, E-mail: maciejbanach77@gmail.com

Published on behalf of the European Society of Cardiology. All rights reserved. (c) The Author(s) 2018. For permissions, please email: journals.permissions@oup.com. 
Conclusion Low HDL-C was associated with reduced risk of incident CHD in black participants suggesting a potential HDL paradox for incident CHD. Very low HDL-C in women was significantly associated with cancer mortality in a fully adjusted complete case model.

Keywords
Cholesterol - Coronary heart disease
- Malignant disease
- Mortality

\section{Introduction}

In the 1970s, the Framingham Heart Study (FHS) demonstrated an inverse correlation between plasma high-density lipoprotein cholesterol (HDL-C) concentrations and coronary heart disease (CHD) risk, ${ }^{1}$ an observation that was consistent with previous descriptions of the role of $\mathrm{HDL}$ in reverse cholesterol transport ${ }^{2}$ and which prompted investigations into the therapeutic potential of HDL-elevating interventions. Despite early promise, ${ }^{3}$ recent trials with niacin or cholesteryl ester transfer protein (CETP) inhibitors failed to demonstrate that treatment to raise $\mathrm{HDL}-\mathrm{C}$ resulted in improved cardiovascular $(\mathrm{CV})$ health outcomes. ${ }^{4,5}$ A study employing Mendelian randomization demonstrated that several polymorphisms, which raised HDL-C did not reduce the risk of myocardial infarction (MI). ${ }^{6}$ Furthermore, it has recently been shown that a rare variant of the scavenger receptor B1 is associated with increased HDL-C and an increased risk of CHD. ${ }^{7}$ These data suggest that $\mathrm{HDL}-\mathrm{C}$ is not implicated in the causal pathway of atherosclerosis.

The accumulation of evidence therefore casts doubt on HDLelevation as a therapeutic strategy. However, the risk conferred by low HDL-C can be ameliorated-a post hoc analysis of the Justification for the Use of Statins in Prevention: an Intervention Trial Evaluating Rosuvastatin (JUPITER) trial has shown benefit of statins in this respect. $^{8,9}$ Thus, the inverse relationship between HDL-C and clinical outcomes necessitates careful study to enable identification of patients at risk and to offer risk reduction therapies where they are available. While individuals with $\mathrm{HDL}-\mathrm{C}<40 \mathrm{mg} / \mathrm{dL}$ are recognized at being increased risk of CV events, currently relatively little is known about the health outcomes associated with very low $(<30 \mathrm{mg} / \mathrm{dL}) \mathrm{HDL}-\mathrm{C}$. Most studies conducted to date have been underpowered to detect such differences. One observational study including 43368 subjects, 429 of whom had HDL-C $<15 \mathrm{mg} / \mathrm{dL}$, showed that most cases of very low HDL-C were associated with secondary causes and that mortality was significantly elevated when HDL-C concentrations were $<15 \mathrm{mg} / \mathrm{dL} .{ }^{10}$

We analysed data from the REasons for Geographical And Racial Differences in Stroke (REGARDS) study to investigate the relationships between low $(30-39.9 \mathrm{mg} / \mathrm{dL})$ and very low $(<30 \mathrm{mg} / \mathrm{dL})$ concentrations of HDL-C and CHD incidence, death and all-cause mortality. In light of previous observations of inverse relationship between HDL-C and cancer, ${ }^{11}$ we also included malignant disease as an endpoint in our analysis. The large size of the cohort and the recruitment strategy of the REGARDS study allowed these relationships to be investigated in racial subgroups and for comparisons to be made between the sexes.

\section{Methods}

\subsection{REGARDS study population}

The REGARDS longitudinal cohort study recruited 30239 communitydwelling subjects between January 2003 and October 2007. ${ }^{12}$ Participants were selected from commercially available lists and recruited through a combination of mail and telephone contact. Because of a focus on geographic and racial disparities in stroke mortality, blacks were oversampled (44\%), as were residents of the southeastern U.S. Stroke Belt states (56\%). ${ }^{12,13}$ The Stroke Belt states were defined as NC, SC, GA, TN, AL, MS, AR, and LA, with the remaining $44 \%$ of the participants selected from the remaining 40 contiguous USA. ${ }^{12,13}$

Eligibility criteria included having a name and telephone number in the Gensys database, black or white race, English-speaking, aged 45 and older, absence of conditions associated with a life expectancy of less than 5 years, living in the community, and not being in or on a waiting list for a nursing home. Potential participants with diagnosed malignancy at baseline were excluded, those with medical conditions that would preclude long-term participation, and being cognitive impairment as judged by the telephone interviewer. ${ }^{12}$ The participation rate was estimated as $33 \%$, similar to other studies. ${ }^{13}$

The REGARDS study protocol was approved by the Institutional Review Boards governing research in human subjects at the participating centres. All participants provided informed consent.

\subsection{Data collection}

For those agreeing to participate, the telephone interviewers conducted an interview to assess cardiovascular disease (CVD) risk factors and medical history. An in-person assessment for direct measurement of risk factors [blood pressure, anthropomorphic characteristics, and electrocardiogram (ECG)] and collection of blood and urine samples was conducted approximately 2-3weeks after the telephone interview. Participants (or their surrogates) were contacted by telephone at 6month intervals to detect suspected CVD events and death, with medical records associated with suspected events retrieved and adjudicated by a physician panel. Additionally, surveillance for death was performed by use of online sources such as the Social Security Death Index (SSDI) and the National Death Index (NDI). Cause of death was established by physician review of medical history, medical records (when available), interviews with next-of-kin or proxies, autopsy reports, death certificates, and the NDI. Details of the study design are provided elsewhere. ${ }^{12}$

In this analysis, we included REGARDS study participants who fasted overnight prior to their study visit, were not missing any explanatory variables of interest, and had valid measurements of total cholesterol, HDLC, and triglycerides. Because the complete case method of analysis has been shown to underestimate risks, especially in black women, we then reanalysed the data, imputing missing values using multiple imputation with chained equations (MICE). ${ }^{14,15}$ REGARDS participants with a history of $\mathrm{CHD}$ at baseline were excluded from the incident $\mathrm{CHD}$ analysis.

Laboratory assays were conducted as previously described. ${ }^{16}$ Samples were centrifuged an average of $97 \mathrm{~min}$ after collection and serum or plasma separated and shipped overnight on ice packs to the University of Vermont as previously described. ${ }^{17}$ On arrival, samples were centrifuged at $30000 \mathrm{~g}$ at $4^{\circ} \mathrm{C}$ and either analysed (general chemistries) or stored at below $-80^{\circ} \mathrm{C}$. C-reactive protein (CRP) was analysed in batches by particle enhanced immunonephelometry using the BNII nephelometer (N High Sensitivity CRP; Dade Behring, Deerfield, IL, USA) with interassay coefficients of variation of $2.1-5.7 \%$. Cholesterol, 
HDL-C, triglycerides, and glucose were measured by colorimetric reflectance spectrophotometry using the Ortho Vitros Clinical Chemistry System 950IRC instrument (Johnson \& Johnson Clinical Diagnostics, New Brunswick, NJ, USA). ${ }^{18}$ LDL-C was calculated using the Friedewald formula from total cholesterol, HDL-C, and triglycerides. ${ }^{19}$

Demographic factors included participant age, race (black/white), and sex. Measures of socio-economic status (SES) included self-reported income level ( $<\$ 20 \mathrm{k}, \$ 20-\$ 34 \mathrm{k}, \$ 35-\$ 74 \mathrm{k}$, and $\geq \$ 75 \mathrm{k})$ and education level (less than high school, high school graduate, some college, and college graduate). Alcohol consumption (some, none), physical activity (none, 1-3 times/week, 4 or more times/week), and current cigarette smoking were assessed during the baseline telephone interview. Diabetes was defined as self-reported diabetes medication use or fasting glucose $\geq 126 \mathrm{mg} / \mathrm{dL}$. Body mass index (BMI) $\left(\mathrm{kg} / \mathrm{m}^{2}\right)$ and systolic blood pressure $(\mathrm{mmHg})$ were measured during the in-home visit. Albumin-tocreatinine ratio $(A C R \geq 30$ vs. $<30 \mathrm{mg} / \mathrm{g}$ ), estimated glomerular filtration rate (eGFR) through the Chronic Kidney Disease Epidemiology Collaboration (CKD-EPI) equation, ${ }^{20} \mathrm{CRP}(<1 \mathrm{mg} / \mathrm{L}, 1-3 \mathrm{mg} / \mathrm{L}, \geq 3 \mathrm{mg} /$ $\mathrm{L})$, low-density lipoprotein (LDL), and triglycerides were measured through specimens. Use of statins, other lipid-lowering medications (fibrates or niacin) and steroids was based on medication inventory.

\subsection{Endpoints}

The three endpoints of interest were: (i) death from any cause, (ii) death from malignant disease, and (iii) incident fatal or non-fatal CHD, each at or before 31 December 2013 (the last date where adjudication of the cause of death was available). The definition of incident CHD has been previously described as an incident definite or probable non-fatal $\mathrm{Ml}$ or $\mathrm{CHD}$ death. ${ }^{17} \mathrm{MI}$ was classified based on published guidelines and consideration of clinical signs and symptoms consistent with ischaemia; a rising and/or falling pattern of biomarkers over at least $6 \mathrm{~h}$ with a peak at least twice the upper limit of normal; and ECG or other imaging findings consistent with ischaemia. REGARDS study participants or proxy respondents were contacted every 6 months via telephone to assess incident $\mathrm{CHD}$ events. Medical records were retrieved for adjudication for suspected events. When fatal CHD events were reported, interviews with next-of-kin or proxies, medical records in the last year of life, death certificates, and autopsy reports were examined to determine if a CHD event was the main underlying cause of death. Non-fatal Mls and fatal $\mathrm{CHD}$ events were adjudicated by trained clinicians following published guidelines. ${ }^{21-23}$ For all analysis of incident CHD, those participants with baseline CHD (self-reported Ml, coronary artery bypass grafting, angioplasty or stenting, or evidence of MI via ECG) were excluded.

Cancer mortality was recorded regardless of cancer type, as previously described. ${ }^{24}$ Cancer mortality was assessed through semi-annual telephone follow-up, death information from participant proxies, linkages with the SSDI and the NDI. Date of death was confirmed using death certificates, SSDI and/or NDI, and cause of death was adjudicated by a committee of experts using all available information as recommended by national guidelines. ${ }^{17}$

\subsection{Statistical analysis}

HDL-C categories were defined by fasting HDL-C measurement into the following categories: 'very low' HDL-C ( $<30 \mathrm{mg} / \mathrm{dL})$, 'low' HDL-C (30-<40 mg/dL), and 'normal' HDL-C ( $\geq 40 \mathrm{mg} / \mathrm{dL}$ ) (reference value). To assess the association between the HDL-C categories and each outcome (a series of incremental Cox proportional hazards models were employed on complete cases: Model 1) adjustment for demographic factors (age, race, sex; Model 2) additional adjustment for SES (income level and education level, alcohol consumption, physical activity, smoking, and BMI; Model 3) additional adjustment for diabetes (estimated eGFR, ACR, CRP, statin use, other lipid-lowering medication use, steroid use, and, Model 4) additional adjustment for LDL-C and triglycerides. Statistical interactions in the minimally adjusted model (Model 1) and final model (Model 4) were used to examine whether the associations between HDL-C category and the outcomes varied by sex and race, separately. In a separate analysis, Model 4 was used to interrogate the data using MICE. ${ }^{14,15}$ For the incremental proportional hazards models, the level of significance was set at 0.05 , and 0.10 for the interaction analyses. ${ }^{25} \mathrm{~A}$ sensitivity analysis further explored whether the association between HDL-C category and each outcome changes over time, using a joint Wald test of time-varying HDL-C effects in Model 4. Additional sensitivity analyses examined continuous HDL-C using restricted cubic splines in Model 4 as well as HDL-C quintiles in Models 1 and 4. SAS 9.4 (SAS Institute, Inc., Cary, NC, USA), and $\mathrm{R}^{26}$ were used for all complete case statistical analyses and STATA 14.2 for multiple imputation analyses.

\section{Results}

\subsection{Baseline characteristics}

Of the 21751 participants that met the complete case inclusion criteria (Supplementary material online, Figure S1), $45 \%$ of them were male and $39 \%$ were black. The mean age was $64.6( \pm 9.4)$ years. With respect to HDL-C, 748 (3.4\%) participants were in the very low (<30 mg/dL) HDLC category; 4038 (18.6\%) in the low $(30-<40 \mathrm{mg} / \mathrm{dL})$, and 16965 (78.0\%) were in the normal ( $\geq 40 \mathrm{mg} / \mathrm{dL})$ category.

Age, BMl, eGFR, educational status, income, physical activity, smoking, statin use, and CRP were broadly similar between the categories. Participants in the low and very low HDL categories were more likely to be male, white, and to have diabetes than participants with normal HDL. HDL category was directly correlated with LDL-C and inversely correlated with triglycerides. Baseline characteristics for the population (stratified by HDL-C category) are shown in Supplementary material online, Table S1. Detailed number of events and populations for each HDL*ace and $\mathrm{HDL}^{*}$ sex group is presented in Supplementary material online, Table S2. Hazard ratios (HRs) describing the association between HDL$\mathrm{C}$ category and risk of all-cause mortality, mortality from malignant disease and incident CHD are presented in Supplementary material online, Table S3, and HRs describing the association between HDL-C quintile and each outcome of interest by race and sex are presented in Supplementary material online, Tables S4 and S5, respectively. Relative hazard of each outcome using continuous HDL-C through restricted cubic splines by race and sex are presented in Supplementary material online, Figures S2-S7.

\subsection{Relationship between HDL-C category and all-cause mortality}

The mean person-years follow-up (SD) for all-cause mortality was 7.2 (2.5) years. Unadjusted Kaplan-Meier curves showed that, compared with participants in the normal HDL-C category, all-cause mortality was higher in patients with low or very low HDL-C (Figure 1). In Cox proportional hazard models adjusted for age, race, and sex (Model 1), participants in the low category of HDL-C had greater risk of death with the HR 1.15 [95\% confidence interval (CI): 1.06-1.25] and the mortality in the very low HDL-C group was greater still 1.48 (95\% Cl 1.28-1.73), thus demonstrating a monotonic relationship between HDL-C and 
mortality. Similar results were seen after further adjustment for education level, income level, alcohol consumption, physical activity, smoking, and BMI (Model 2). Further adjustment (Models 3 and 4) attenuated this relationship, as did analysis by MICE (Supplementary material online, Table S3). There is no evidence that the association between HDL-C category and all-cause mortality changes over time $(P=0.12)$.

In the fully adjusted model (Model 4), statistically significant differences were observed between males and females in the relationship between HDL-C and all-cause mortality ( $P$ for interaction $=0.08)$ with numerically larger $H R$ in females (HR 1.31, 95\% Cl 0.88-1.95 for HDL$C<30 \mathrm{mg} / \mathrm{dL}$ ). However, no statistically significant differences between sexes were observed when MICE was employed (Table 1). Neither complete case analysis (Model 4) nor MICE demonstrated a statistically significant interaction of race with respect to all-cause mortality (Table 2). Treating HDL-C continuously, no differences in association with allcause mortality were observed by race $(P=0.65$; Supplementary material online, Figure S2), but the interaction between HDL-C and sex was statistically significant $(P<0.01$; Supplementary material online, Figure S3).

\subsection{Relationship between HDL-C and cancer-specific mortality}

The mean person-years follow-up (SD) for cancer-specific mortality was 7.8 (2.8) years. Unadjusted Kaplan-Meier curves showed that, compared with participants in the normal HDL-C category, the rate of cancer mortality was increased in patients with low or very low HDL-C (Figure 2), which were apparent before 2 years and extend through 10 years of follow-up. In Cox proportional hazard models adjusted for age, race, and sex (Model 1), participants in the low and very low categories of HDL-C had increased risk of cancer-specific mortality-HR 1.14 (95\% Cl 0.991.32 ) and 1.35 (95\% $\mathrm{Cl} 1.03-1.77)$, respectively, and this trend continued through models 2, 3, and 4 with gradual effect attenuation, and the effect was not observed with MICE (Supplementary material online, Table S3). There is no evidence that the association between HDL-C category and cancer-specific mortality changes over time $(P=0.08)$. In the fully adjusted model (Model 4), using complete case analysis, statistically significant differences were observed between males and females in the relationship between HDL-C and cancer-specific mortality ( $P$ for interaction $=0.014)$. In females, the very low category of HDL-C was strongly associated with the higher risk of cancer (HR 2.31, 95\% Cl 1.28-4.16) compared with men (HR 0.88, 95\% Cl 0.64-1.21) (Table 1). The difference between cancer mortality between males and females was also seen when MICE was employed $(P=0.033)$. Neither complete case analysis (Model 4) nor MICE demonstrated a statistically significant interaction of race with respect to cancer-specific mortality (Table 2). Examining HDL-C continuously, no differences in association with cancer-specific mortality were observed by race $(P=0.62$; Supplementary material online, Figure S4) but the interaction between HDL-C, and sex was statistically significant $(P<0.01$; Supplementary material online, Figure S5).

\subsection{Relationship between HDL-C and inci- dent CHD}

The mean person-years follow-up (SD) for all-cause mortality was 7.0 (2.6) years. Unadjusted Kaplan-Meier curves showed that, compared with participants in the normal HDL-C category, rates of incident CHD were increased in patients with low or very low HDL-C (Figure 3), which were apparent before 2 years and extend through 10 years of follow-up.

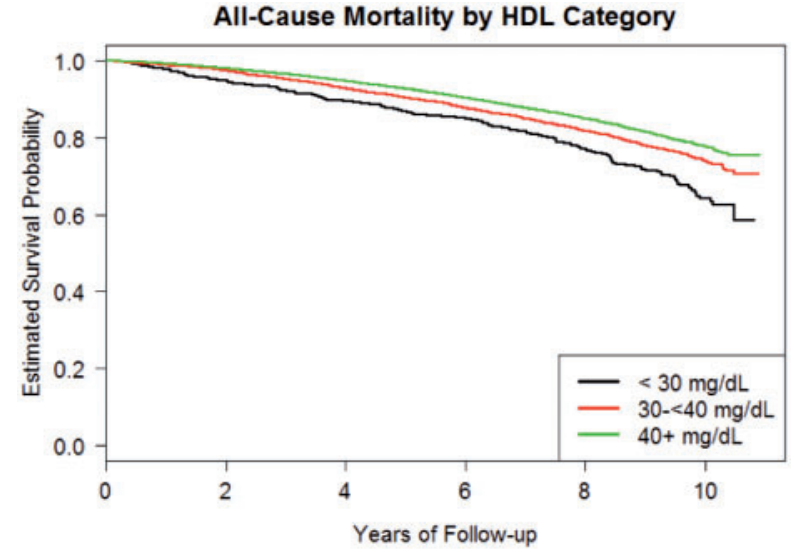

Figure I Unadjusted Kaplan-Meier survival curves with estimates for survival probability for all-cause mortality for each of the three HDL-C categories.

In adjusted Cox proportional hazard models (Models 1-4) the observed effect was gradually attenuated together with subsequent adjustments (Supplementary material online, Table S3). There is no evidence to suggest that the association between HDL-C category and incident $\mathrm{CHD}$ varies over time $(P=0.08)$.

Subgroup analysis of the fully adjusted model (Model 4) using the complete case method demonstrated statistically significant effects of sex $($ Table 1$)(P$ for interaction $=0.008)$ and race $($ Table 2$)(P$ for interaction $=0.018)$. The analysis of the relationship between HDL-C and incident CHD in females showed that low HDL-C (30-39.9 mg/dL) was significantly associated with a reduced risk of incident CHD (HR 0.57, 95\% Cl 0.38-0.86); conversely, very low HDL-C was non-significantly associated with greater risk (HR 1.57, 95\% Cl 0.69-3.58). In males, a different relationship was seen with no effect of low HDL-C (HR 1.04, 95\% Cl 0.85-1.28), or very low HDL-C (HR 0.82, 95\% Cl 0.55-1.22) on incident CHD. However, these sex differences were not replicated when analysis was performed using MICE (Table 1). In whites, participants in the low HDL-C category had a similar incidence of CHD as those in the normal (reference) category (HR 1.09, 95\% Cl 0.88-1.35), similar results were seen with very low HDL-C (HR 0.92, 95\% Cl 0.61-1.39). Black participants in the low HDL-C category were at significant lower risk of incident CHD than those with normal HDL-C (HR 0.63, 95\% Cl 0.460.88 ), and a similar trend (however not significant) was seen with the very low HDL-C group (HR 0.82, 95\% Cl 0.40-1.68). The significant interaction of race in complete case analysis was preserved when MICE analysis was employed $(P$ for interaction $=0.054)($ Table 2$)$. Significant differences in the association between continuous HDL-C and incidence of $\mathrm{CHD}$ were observed by both race $(P=0.02$; Supplementary material online, Figure $S 6)$ and sex $(P=0.04$; Supplementary material online, Figure S7).

\section{Discussion}

Our study has demonstrated that HDL-C tertiles were inversely monotonically associated with all-cause mortality and cancer-specific mortality in a minimally adjusted model. A similar trend was seen with the 
Table I HRs describing the association between HDL-C category and risk of all-cause mortality, mortality from malignant disease and incident CHD by sex

\begin{tabular}{|c|c|c|c|c|c|c|c|c|}
\hline & & & \multicolumn{2}{|c|}{ Complete Case Model $1^{a}$} & \multicolumn{2}{|c|}{ Complete Case Model $4^{a}$} & \multicolumn{2}{|l|}{ MICE Model $4^{a}$} \\
\hline & & & Female & Male & Female & Male & Female & Male \\
\hline \multirow{3}{*}{$\begin{array}{l}\text { All-cause } \\
\text { mortality }\end{array}$} & \multirow[t]{2}{*}{ HDL strata } & $<30 \mathrm{mg} / \mathrm{dL}$ & $2.42(1.64-3.56)$ & $1.35(1.15-1.59)$ & $1.31(0.88-1.95)$ & $0.90(0.81-1.07)$ & $1.14(0.83-1.57)$ & $0.79(0.56-1.11)$ \\
\hline & & $>40 \mathrm{mg} / \mathrm{dL}$ & 1 (ref) & 1 (ref) & 1 (ref) & 1 (ref) & 1 (ref) & 1 (ref) \\
\hline & \multicolumn{2}{|c|}{$P$ for interaction } & \multicolumn{2}{|c|}{$P<0.0001$} & \multicolumn{2}{|c|}{$P=0.08$} & \multicolumn{2}{|c|}{$P=0.16$} \\
\hline \multirow{2}{*}{$\begin{array}{c}\text { Cancer-specific } \\
\text { mortality }\end{array}$} & HDL strata & $>40 \mathrm{mg} / \mathrm{dL}$ & 1 (ref) & 1 (ref) & 1 (ref) & 1 (ref) & 1 (ref) & 1 (ref) \\
\hline & \multicolumn{2}{|c|}{$P$ for interaction } & \multicolumn{2}{|c|}{$P=0.003$} & \multicolumn{2}{|c|}{$P=0.014$} & \multicolumn{2}{|c|}{$P=0.033$} \\
\hline \multirow[t]{3}{*}{ Incident CHD } & HDL strata & $<30 \mathrm{mg} / \mathrm{dL}$ & $2.75(1.23-6.18)$ & $1.29(0.89-1.88)$ & $1.57(0.69-3.58)$ & $0.82(0.55-1.22)$ & $1.07(0.60-1.90)$ & $0.92(0.50-1.70)$ \\
\hline & & $30-<40 \mathrm{mg} / \mathrm{dL}$ & $0.86(0.58-1.28)$ & $1.29(1.06-1.57)$ & $0.57(0.38-0.86)$ & $1.04(0.85-1.28)$ & $0.82(0.63-1.07)$ & $1.23(0.92-1.63)$ \\
\hline & & $>40 \mathrm{mg} / \mathrm{dL}$ & 1 (ref) & 1 (ref) & 1 (ref) & 1 (ref) & 1 (ref) & 1 (ref) \\
\hline
\end{tabular}

CHD, coronary heart disease; HDL-C, high-density lipoprotein cholesterol; MICE, Multiple Imputation by Chained Equations.

aModel 1 estimates are adjusted for age, race, and sex. Model 4 estimates are additionally adjusted for education level, income level, alcohol consumption, physical activity, current smoking, BMI, diabetes, ACR, eGFR, use of statins, use of other lipid-lowering medications (fibrates/niacin), use of steroids, hsCRP, c-C, and triglycerides.

Table 2 HRs describing the association between HDL-C category and risk of all-cause mortality, mortality from malignant disease and incident CHD by race

\begin{tabular}{|c|c|c|c|c|c|c|c|c|}
\hline & & & \multicolumn{2}{|c|}{ Complete Case Model $1^{a}$} & \multicolumn{2}{|c|}{ Complete Case Model $4^{a}$} & \multicolumn{2}{|l|}{ MICE Model $4^{\mathrm{a}}$} \\
\hline & & & Black & White & Black & White & Black & White \\
\hline \multirow{3}{*}{$\begin{array}{l}\text { All-cause } \\
\text { mortality }\end{array}$} & \multirow[t]{2}{*}{ HDL strata } & $<30 \mathrm{mg} / \mathrm{dL}$ & $1.67(1.26-2.22)$ & $1.43(1.20-1.70)$ & $1.19(0.89-1.59)$ & $0.88(0.74-1.06)$ & $0.96(0.72-1.28)$ & $0.96(0.82-1.12)$ \\
\hline & & $>40 \mathrm{mg} / \mathrm{dL}$ & 1 (ref) & 1 (ref) & 1 (ref) & 1 (ref) & 1 (ref) & 1 (ref) \\
\hline & \multicolumn{2}{|c|}{$P$ for interaction } & \multicolumn{2}{|c|}{$P=0.64$} & \multicolumn{2}{|c|}{$P=0.21$} & \multicolumn{2}{|c|}{$P=0.61$} \\
\hline \multirow{2}{*}{$\begin{array}{c}\text { Cancer-specific } \\
\text { mortality }\end{array}$} & HDL strata & $>40 \mathrm{mg} / \mathrm{dL}$ & 1 (ref) & 1 (ref) & 1 (ref) & 1 (ref) & 1 (ref) & 1 (ref) \\
\hline & \multicolumn{2}{|c|}{$P$ for interaction } & \multicolumn{2}{|c|}{$P=0.95$} & \multicolumn{2}{|c|}{$P=0.87$} & \multicolumn{2}{|c|}{$P=0.98$} \\
\hline \multirow[t]{3}{*}{ Incident CHD } & \multirow[t]{3}{*}{ HDL strata } & $<30 \mathrm{mg} / \mathrm{dL}$ & $1.18(0.58-2.39)$ & $1.51(1.02-2.22)$ & $0.82(0.40-1.68)$ & $0.92(0.61-1.39)$ & $0.76(0.50-1.17)$ & $1.06(0.83-1.35)$ \\
\hline & & $30-<40 \mathrm{mg} / \mathrm{dL}$ & $0.81(0.59-1.12)$ & $1.42(1.16-1.74)$ & $0.63(0.46-0.88)$ & $1.09(0.88-1.35)$ & $0.76(0.58-0.98)$ & $1.06(0.91-1.24)$ \\
\hline & & $>40 \mathrm{mg} / \mathrm{dL}$ & 1 (ref) & 1 (ref) & 1 (ref) & 1 (ref) & 1 (ref) & 1 (ref) \\
\hline
\end{tabular}

CHD, coronary heart disease; HDL-C, high-density lipoprotein cholesterol; MICE, Multiple Imputation by Chained Equations.

a Model 1 estimates are adjusted for age, race, and sex. Model 4 estimates are additionally adjusted for education level, income level, alcohol consumption, physical activity, current smoking, BMI, diabetes, ACR, eGFR, use of statins, use of other lipid-lowering medications (fibrates/niacin), and use of steroids.

relationship between HDL-C and the risk of incident CHD. Analysis of racial subgroups revealed that blacks in the 'low' and 'very low' HDL-C categories experienced fewer incident $\mathrm{CHD}$ events than those with 'normal' HDL-C using both complete case and MICE analysis methods. Thus, in this population, our data suggest an HDL paradox, raising the possibility of the existence of an inverted $U$ - or J-curve phenomenon. Subgroup analysis of a fully adjusted complete case model revealed striking differences between males and females. The interaction with sex was significant for all three outcomes, with low HDL-C being prognostic of poorer outcomes in females than in males in each case. In particular, in females, 'very low' HDL was strongly associated with cancer-specific mortality, whereas such an effect was not seen in males. This interaction of sex was also observed in MICE analysis, however the effect was slightly attenuated (HR goes from 2.31 in complete case to 1.81 in MICE). It has long been recognized that population-level HDL-C concentrations are higher in adult females than males. ${ }^{27}$ Thresholds for diagnosing low HDL-C differ between the genders $(<40 \mathrm{mg} / \mathrm{dL}$ in men and $<50 \mathrm{mg} / \mathrm{dL}$ in women). ${ }^{28} \mathrm{~A}$ similar inverse relationship between HDL-C and incident cancer has been previously observed in a Chinese cohort study including 17779 participants. ${ }^{29}$ Furthermore, a study-level metaanalysis of 625000 participants demonstrated a 36\% lower incidence of cancer for every $10 \mathrm{mg} / \mathrm{dL}$ increase in HDL-C. ${ }^{11}$ The fact that our study complements findings conducted in very different demographic groups and using different methodologies is reassuring. 


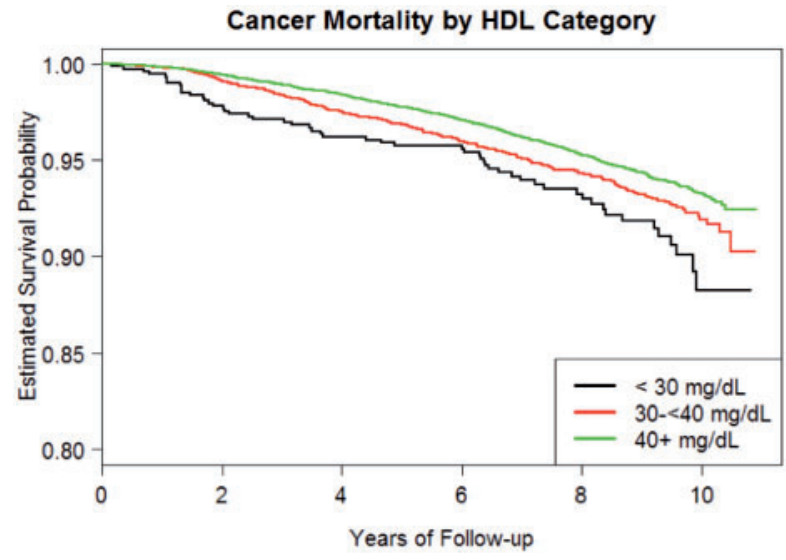

Figure 2 Unadjusted Kaplan-Meier survival curves with estimates for survival probability for cancer mortality for each of the three HDLC categories.

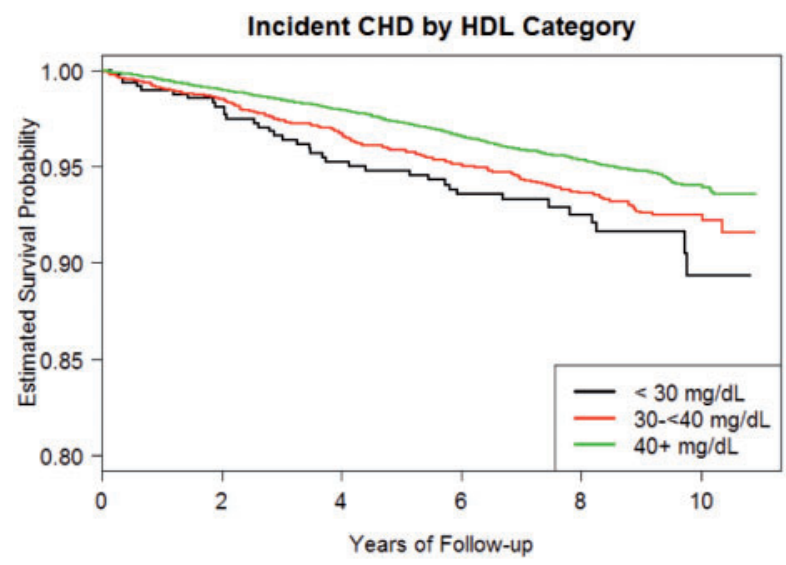

Figure 3 Unadjusted Kaplan-Meier survival curves with estimates for survival probability for incident coronary heart disease for each of the three HDL categories.

The results of this study suggest the possibility that HDL-C may be prognostically useful in clinical practice beyond the calculation of CVD risk, particularly for women. The poor predictive value of HDL-C against CHD among the whole population in this study is consistent with results obtained by Mendelian randomization ${ }^{6}$ that demonstrate that a causal relationship between low HDL-C and $\mathrm{Ml}$ is unlikely. Our results are consistent with those of Tada et al. ${ }^{10}$ who conducted an observational study of subjects attending hospital in Japan and whose HDL-C was measured for any reason. Out of a cohort of 43368 patients, 429 were found to have 'extremely low' HDL-C $(<15 \mathrm{mg} / \mathrm{L})$, and mortality was greatest in this group. During the median 175 days follow-up period, 106 patients in this group died. It is possible that infectious diseases are partially responsible for excess mortality in participants with very low HDL-C. Our study did not investigate this hypothesis, however, recent findings from the Copenhagen City Heart Study indicate that HDL-C $<31 \mathrm{mg} / \mathrm{dL}$ (almost identical to our 'very low' HDL-C group) was associated with a HR of 1.75 for infectious disease compared with normal HDL-C. ${ }^{30}$ This likely reflects the important roles of HDL in immunity and the modulations of HDL function during infectious and inflammatory states. HDL particles influence the activity of monocytes, macrophages, dendritic cells, and T- and B- lymphocytes by altering the cholesterol content of lipid rafts. ${ }^{31} \mathrm{HDL}$ limits the potential for bacterial lipopolysaccharide to induce inflammatory reactions. ${ }^{31}$ However, rapid reductions of HDL-C have been observed during acute infections, ${ }^{31}$ and inflammatory states can result in 'dysfunctional' HDL which can exert pro-inflammatory effects. ${ }^{32}$ Similarly, cytokine release associated with the inflammatory response to tumours has been associated with reduced plasma concentrations of HDL-C. ${ }^{33}$

Probably the remaining question is whether the relationship between low HDL-C and poor outcomes is causal, or whether low HDL-C occurs secondary to another condition, which results in morbidity and mortality. Rader and de Goma reviewed the causes of low HDL-C, which they divided into artifactual causes (e.g. assay interference by paraproteinemia), primary (monogenic) causes [e.g. ApoA-I deficiency or mutation, Tangier disease, heterozygous deficiency of ATP-binding cassette transporter A1 (ABCA1), lecithin cholesterol acyltransferase (LCAT) deficiency], all of which are uncommon and secondary causes (e.g. anabolic androgenic steroids, malignancy, and idiosyncratic response to fibrates). ${ }^{34}$ In the recent study by Tada et al., most cases of low HDLC were attributable to secondary causes. As many as 80 (75\%) of the causes of death were either from malignancies, inflammatory diseases, or major bleeding, in contrast to a relatively low mortality from CVD $(10 \%) .{ }^{10}$ That observation is consistent with the finding of this study that low HDL-C was a better predictor of all-cause mortality and cancer mortality than it was for incident CHD in complete case analysis. However, the results of these studies may not be directly comparable in this respect because Tada et al. included in their analysis all patients found to have low HDL-C, whereas in this study, participants with malignancy at baseline were not included in REGARDS and patients with $\mathrm{CHD}$ at baseline were excluded from the analysis. Thus, in contrast to the study by Tada et al., in which most of the very low cases of HDL-C were attributable to secondary causes, our study might be considered to focus on the lowest identifiable levels of primary low HDL-C. This is reflected in different cut-off points in the categorization of 'extremely low' HDL: <20 mg/dL in Tada et al., compared with 'very low' $<30$ mg/dL in this study, which resulted in $3.5 \%$ of our population being included in this group.

Recent findings suggest that the inverse relationship between HDL-C and triglycerides low HDL-C could be attributed to hypertriglyceridaemia via augmentation of CETP activity. ${ }^{35}$ Furthermore, the incidence of diabetes was much greater in participants with low and very low HDL-C, than those in the 'normal' category. The existence of dysfunctional, proinflammatory HDL-C in diabetes has been described elsewhere. ${ }^{36}$ In this study, the prognostic effects of HDL-C in the whole study population were attenuated when the Cox-regression Model 2 correcting for BMI was applied, and further attenuation was seen with Model 3, which corrects for diabetes (among other factors).

Our results suggest a protective effect of HDL-C against cancer. Several lines of investigation indicate that such an effect is biologically plausible. Apolipoprotein A-1, the constituent lipoprotein of HDL-C has been demonstrated to inhibit tumour development in mouse models of ovarian cancer ${ }^{37}$ and melanoma ${ }^{38}$ and L-5F, an apolipoprotein mimetic has been shown to inhibit tumour angiogenesis. ${ }^{39}$ Other components of the cholesterol efflux/reverse cholesterol transport pathway may be 
involved in the regulation of malignancy. It has recently been demonstrated in mouse models that knockout of ATP-binding cassette transporters $A B C A 1$ and $A B C G 1$ is protective against melanoma growth and metastasis. ${ }^{40}$

Few populations have a sufficient number of black participants to powerfully assess racial differences in the role of $\mathrm{HDL}$ and disease risk. A potentially new finding of this study is the association of lower CHD risk in blacks with HDL-C levels $<40 \mathrm{mg} / \mathrm{dL}$, thus apparently exhibiting an 'HDL paradox'. These results, however, should be interpreted with caution, especially as the relatively small numbers of participants in the racial subgroups of patients with low HDL-C weakened the statistical power of these analyses. Nevertheless, it should be noted that the phenomenon was observed after both complete case analysis and MICE, reducing the likelihood of an artifactual finding. This is an interesting finding that requires further investigation, perhaps in other large cohorts and registries. Racial differences in the prognostic utility of HDL-C in CVD risk prediction have been observed before, and a similar paradoxical effect of very low HDL-C has been observed in Asians. ${ }^{41}$ A previous analysis of data from black participants in the REGARDS study failed to find an association between low HDL-C (defined as $<40 \mathrm{mg} / \mathrm{dL}$ in men or $<50 \mathrm{mg} / \mathrm{dL}$ in women) and incident CHD. ${ }^{42}$ Trends indicating similar paradoxically protective effects of 'low' or 'extremely low' HDL-C were seen in other subgroups (all-cause mortality in males and whites; cancer mortality in males; and incident CHD in males). None of these latter trends were statistically significant, however, it is possible that the study was underpowered to detect such effects because of the relatively small number of participants in the 'low' and 'extremely low' HDL-C categories. Differences in outcomes in different racial groups may reflect varying prevalence of genetic traits relating to HDL-C. Associations of HDLC, CVD, and genetic variants have been discussed elsewhere, ${ }^{43,44}$ and recently a rare variant of the scavenger receptor $\mathrm{B} 1$ has been found to be associated with increased HDL-C and an increased risk of CHD. ${ }^{7}$ Further investigations of this type may open the possibility for personalized risk prediction after genetic testing.

\subsection{Study strengths and limitations}

The large sample size, long period of follow-up, and rigorous approach to data collection in the REGARDS study make this cohort an extremely useful tool to explore relationships between biomarkers and risks of disease. Nevertheless, such an approach to research has several limitations. Observational studies, such as this, cannot demonstrate causality and are vulnerable to bias by unknown or unmeasured factors. In this analysis, we have performed both complete case and MICE analysis in order to address these difficulties. Complete case analysis has the limitation that it can underestimate risks in some subgroups. MICE analysis assumes that the probability a variable is missing depends only on observed covariates is based on the missing-at-random assumption and is sensitive to departures from this assumption, increasingly so with larger amounts of missing data. ${ }^{45}$ Thus, we have provided both analyses for comparison and for completeness.

In common with many other studies, our analyses are based upon measurement of plasma lipids at a single point in time, and could be confounded by undiagnosed disease (particularly malignancies) at baseline. LDL-C in this study was calculated by the Friedewald equation, and therefore likely represents the sum of LDL-C, lipoprotein (a) and intermediate-density lipoprotein cholesterol. ${ }^{19}$ Greater precision could have been obtained by direct measurement of LDL-C, however, as the focus of this study was HDL-C, this would be unlikely to affect our findings. Other investigators have described a phenomenon of falsely low measurements of $\mathrm{HDL}^{46}$ although such artifactual errors are likely to be rare. However, even with this potential measurement error the associations discussed were sufficiently strong for detection; and importantly we do not know why measurement error would differ between racial groups, and as such would not affect the interesting observations with respect to race. In this investigation, similar to the results of other investigators, ${ }^{10}$ there was a very uneven distribution of patients across the categories of HDL-C, limiting statistical power, in particular in the very low category of $\mathrm{HDL}$, and precluding the study of even lower categories of HDL-C. Since our analysis includes all available participants for effect estimation, we are unable to investigate the potential confounding of female-specific measures such as menopause or hormone replacement therapy on the relationship between HDL-C and our endpoints. Our study focuses only on health outcomes associated with low HDL-C. Health outcomes associated with exceptionally high HDL-C will be investigated in future studies.

\section{Conclusions}

Low HDL-C was associated with increased risk for all-cause mortality, cancer mortality, and incident CHD in a minimally adjusted model, however the effect was attenuated in fully adjusted model. When complete case analysis was used, for all three outcomes considered, the sex-HDL$C$ interaction was significant with poorer outcomes associated with low HDL-C in women than men. Further, the relationship with cancer mortality appears to be specific to women. Using both complete case analysis and MICE, we observed the existence of an 'HDL paradox', whereby low HDL-C associated with lower risk of incident CHD was observed in black participants of the REGARDS study.

\section{Supplementary material}

Supplementary material is available at Cardiovascular Research online.

\section{Acknowledgements}

The authors thank the investigators, staff, and participants of the REGARDS study for their valuable contributions. A full list of participating REGARDS investigators and institutions can be found at http://www. regardsstudy.org.

\section{Conflict of interest: none declared.}

\section{Funding}

This research project is supported by cooperative agreement U01 NS041588 from the National Institute of Neurological Disorders and Stroke (NINDS), National Institutes of Health, and Department of Health and Human Service. Additional funding came from R01 HL080477 from the National Heart Lung and Blood Institute (Bethesda, MD). The content is solely the responsibility of the authors and does not necessarily represent the official views of NINDS or the National Institutes of Health.

\section{References}

1. Gordon T, Castelli WP, Hjortland MC, Kannel WB, Dawber TR. High density lipoprotein as a protective factor against coronary heart disease. The Framingham Study. Am J Med 1977;62:707-714.

2. Glomset JA. The plasma lecithins: cholesterol acyltransferase reaction. J Lipid Res 1968;9:155-167. 
3. Rubins HB, Robins SJ, Collins D, Fye CL, Anderson JW, Elam MB, Faas FH, Linares E, Schaefer EJ, Schectman G, Wilt T], Wittes J. Gemfibrozil for the secondary prevention of coronary heart disease in men with low levels of high-density lipoprotein cholesterol. Veterans Affairs High-Density Lipoprotein Cholesterol Intervention Trial Study Group. N Engl J Med 1999;341:410-418.

4. Barter PJ, Caulfield M, Eriksson M, Grundy SM, Kastelein JJ, Komajda M, LopezSendon J, Mosca L, Tardif JC, Waters DD, Shear CL, Revkin JH, Buhr KA, Fisher MR, Tall AR, Brewer B; ILLUMINATE Investigators. Effects of torcetrapib in patients at high risk for coronary events. N Engl J Med 2007;357:2109-2122.

5. Toth PP, Barylski M, Nikolic D, Rizzo M, Montalto G, Banach M. Should low highdensity lipoprotein cholesterol (HDL-C) be treated? Best Pract Res Clin Endocrinol Metab 2014;28:353-368.

6. Voight BF, Peloso GM, Orho-Melander M, Frikke-Schmidt R, Barbalic M, Jensen MK, Hindy G, Holm H, Ding EL, Johnson T, Schunkert H, Samani NJ, Clarke R, Hopewell JC, Thompson JF, Li M, Thorleifsson G, Newton-Cheh C, Musunuru K, Pirruccello JP, Saleheen D, Chen L, Stewart A, Schillert A, Thorsteinsdottir U, Thorgeirsson G, Anand S, Engert JC, Morgan T, Spertus J, Stoll M, Berger K, Martinelli N, Girelli D, McKeown PP, Patterson CC, Epstein SE, Devaney J, Burnett MS, Mooser V, Ripatti S, Surakka I, Nieminen MS, Sinisalo J, Lokki ML, Perola M, Havulinna A, de Faire U, Gigante B, Ingelsson E, Zeller T, Wild P, de Bakker PI, Klungel OH, Maitland-van der Zee AH, Peters BJ, de Boer A, Grobbee DE, Kamphuisen PW, Deneer VH, Elbers CC, Onland-Moret NC, Hofker MH, Wijmenga C, Verschuren WM, Boer JM, van der Schouw YT, Rasheed A, Frossard P, Demissie S, Willer C, Do R, Ordovas JM, Abecasis GR, Boehnke M, Mohlke KL, Daly MJ, Guiducci C, Burtt NP, Surti A, Gonzalez E, Purcell S, Gabriel S, Marrugat J, Peden J, Erdmann J, Diemert P, Willenborg C, Konig IR, Fischer M, Hengstenberg C, Ziegler A, Buysschaert I, Lambrechts D, Van de Werf F, Fox KA, El Mokhtari NE, Rubin D, Schrezenmeir J, Schreiber S, Schafer A, Danesh J, Blankenberg S, Roberts R, McPherson R, Watkins H, Hall AS, Overvad K, Rimm E, Boerwinkle E, Tybjaerg-Hansen A, Cupples LA, Reilly MP, Melander O, Mannucci PM, Ardissino D, Siscovick D, Elosua R, Stefansson K, O'Donnell CJ, Salomaa V, Rader DJ, Peltonen L, Schwartz SM, Altshuler D, Kathiresan S. Plasma HDL cholesterol and risk of myocardial infarction: a Mendelian randomisation study. Lancet 2012;380:572-580.

7. Zanoni P, Khetarpal SA, Larach DB, Hancock-Cerutti WF, Millar JS, Cuchel M, DerOhannessian S, Kontush A, Surendran P, Saleheen D, Trompet S, Jukema JW, De Craen A, Deloukas P, Sattar N, Ford I, Packard C, Majumder A, Alam DS, Di Angelantonio E, Abecasis G, Chowdhury R, Erdmann J, Nordestgaard BG, Nielsen SF, Tybjaerg-Hansen A, Schmidt RF, Kuulasmaa K, Liu DJ, Perola M, Blankenberg S, Salomaa V, Mannisto S, Amouyel P, Arveiler D, Ferrieres J, Muller-Nurasyid M, Ferrario M, Kee F, Willer C], Samani N, Schunkert H, Butterworth AS, Howson JM, Peloso GM, Stitziel NO, Danesh J, Kathiresan S, Rader DJ; CHD Exome+ Consortium; CARDloGRAM Exome Consortium; Global Lipids Genetics Consortium. Rare variant in scavenger receptor BI raises HDL cholesterol and increases risk of coronary heart disease. Science 2016;351:1166-1171.

8. Ridker PM, Genest J, Boekholdt SM, Libby P, Gotto AM, Nordestgaard BG, Mora S, MacFadyen JG, Glynn RJ, Kastelein Jj; JUPITER Trail Study Group. HDL cholesterol and residual risk of first cardiovascular events after treatment with potent statin therapy: an analysis from the JUPITER trial. Lancet 2010;376: 333-339.

9. Mora S, Wenger NK, Demicco DA, Breazna A, Boekholdt SM, Arsenault BJ, Deedwania P, Kastelein JJ, Waters DD. Determinants of residual risk in secondary prevention patients treated with high- versus low-dose statin therapy: the Treating to New Targets (TNT) study. Circulation 2012;125:1979-1987.

10. Tada H, Kawashiri MA, Konno T, Nohara A, Inazu A, Mabuchi H, Yamagishi M, Hayashi K. Prevalence, clinical features, and prognosis of patients with extremely low high-density lipoprotein cholesterol. J Clin Lipidol 2016;10:1311-1317.

11. Jafri $\mathrm{H}$, Alsheikh-Ali AA, Karas RH. Baseline and on-treatment high-density lipoprotein cholesterol and the risk of cancer in randomized controlled trials of lipid-altering therapy. J Am Coll Cardiol 2010;55:2846-2854.

12. Howard VJ, Cushman M, Pulley L, Gomez CR, Go RC, Prineas RJ, Graham A, Moy CS, Howard G. The reasons for geographic and racial differences in stroke study: objectives and design. Neuroepidemiology 2005;25:135-143.

13. Morton LM, Cahill J, Hartge P. Reporting participation in epidemiologic studies: a survey of practice. Am J Epidemiol 2006;163:197-203.

14. Rubin DB. Multiple imputation after 18+ years. J Am Stat Assoc 1996;91:473-489.

15. Rubin DB, Schenker N. Multiple imputation in health-care databases: an overview and some applications. Stat Med 1991;10:585-598.

16. Lakoski SG, Le AH, Muntner P, Judd SE, Safford MM, Levine DA, Howard G, Cushman M. Adiposity, inflammation, and risk for death in black and white men and women in the United States: the Reasons for Geographic and Racial Differences in Stroke (REGARDS) study. I Clin Endocrinol Metab 2011;96: 1805-1814.

17. Safford MM, Brown TM, Muntner PM, Durant RW, Glasser S, Halanych JH, Shikany JM, Prineas RJ, Samdarshi T, Bittner VA, Lewis CE, Gamboa C, Cushman M, Howard $\checkmark$, Howard G; REGARDS Investigators. Association of race and sex with risk of incident acute coronary heart disease events. JAMA 2012;308:1768-1774.

18. Cushman M, McClure LA, Howard VJ, Jenny NS, Lakoski SG, Howard G. Implications of increased C-reactive protein for cardiovascular risk stratification in black and white men and women in the US. Clin Chem 2009:55:1627-1636.
19. Friedewald WT, Levy RI, Fredrickson DS. Estimation of the concentration of lowdensity lipoprotein cholesterol in plasma, without use of the preparative ultracentrifuge. Clin Chem 1972;18:499-502.

20. Levey AS, Stevens LA, Schmid CH, Zhang YL, Castro AF 3rd, Feldman HI, Kusek JW, Eggers P, Van Lente F, Greene T, Coresh J; CKD-EPI (Chronic Kidney Disease Epidemiology Collaboration). A new equation to estimate glomerular filtration rate. Ann Intern Med 2009;150:604-612.

21. Luepker RV, Apple FS, Christenson RH, Crow RS, Fortmann SP, Goff D, Goldberg RJ, Hand MM, Jaffe AS, Julian DG, Levy D, Manolio T, Mendis S, Mensah G, Pajak A, Prineas RJ, Reddy KS, Roger VL, Rosamond WD, Shahar E, Sharrett AR, Sorlie P, Tunstall-Pedoe H. AHA Council on Epidemiology and Prevention; AHA Statistics Committee; World Heart Federation Council on Epidemiology and Prevention; European Society of Cardiology Working Group on Epidemiology and Prevention; Centers for Disease Control and Prevention; National Heart, Lung, and Blood Institute. Case definitions for acute coronary heart disease in epidemiology and clinical research studies: a statement from the AHA Council on Epidemiology and Prevention; AHA Statistics Committee; World Heart Federation Council on Epidemiology and Prevention; the European Society of Cardiology Working Group on Epidemiology and Prevention; Centers for Disease Control and Prevention; and the National Heart, Lung, and Blood Institute. Circulation 2003;108:2543-2549.

22. Prineas R, Crow R, Blackburn HW. The Minnesota Code Manual of Electrocardiographic Findings: Standards and Procedures for Measurement and Classification. Boston, MA: Wright-OSG; 1982.

23. Thygesen K, Alpert JS, White HD, Joint ESC/ACCF/AHA/WHF Task Force for the Redefinition of Myocardial Infarction; Jaffe AS, Apple FS, Galvani M, Katus HA, Newby LK, Ravkilde J, Chaitman B, Clemmensen PM, Dellborg M, Hod H, Porela P, Underwood R, Bax J], Beller GA, Bonow R, Van der WEE, Bassand JP, Wijns W, Ferguson TB, Steg PG, Uretsky BF, Williams DO, Armstrong PW, Antman EM, Fox KA, Hamm CW, Ohman EM, Simoons ML, Poole-Wilson PA, Gurfinkel EP, LopezSendon JL, Pais P, Mendis S, Zhu JR, Wallentin LC, Fernandez-Aviles F, Fox KM, Parkhomenko AN, Priori SG, Tendera M, Voipio-Pulkki LM, Vahanian A, Camm AJ, De Caterina R, Dean V, Dickstein K, Filippatos G, Funck-Brentano C, Hellemans I, Kristensen SD, McGregor K, Sechtem U, Silber S, Tendera M, Widimsky P, Zamorano JL, Morais J, Brener S, Harrington R, Morrow D, Lim M, Martinez-Rios MA, Steinhubl S, Levine GN, Gibler WB, Goff D, Tubaro M, Dudek D, Al-Attar N. Universal definition of myocardial infarction. Circulation 2007;116:2634-2653.

24. Akinyemiju T, Moore JX, Pisu M, Lakoski SG, Shikany J, Goodman M, Judd SE. A prospective study of dietary patterns and cancer mortality among Blacks and Whites in the REGARDS cohort. Int J Cancer 2016;139:2221-2231.

25. Selvin S. Statistical Analysis of Epidemiologic Data. Oxford; New York: Oxford University Press; 2004.

26. R Core Team. R: A Language and Environment for Statistical Computing. Vienna, Austria: R Foundation for Statistical Computing; 2016.

27. Lewis B, Chait A, Wootton ID, Oakley CM, Krikler DM, Sigurdsson G, February A, Maurer B, Birkhead J. Frequency of risk factors for ischaemic heart-disease in a healthy British population. With particular reference to serum-lipoprotein levels. Lancet 1974:303:141-146.

28. Schaefer EJ, Anthanont P, Diffenderfer MR, Polisecki E, Asztalos BF. Diagnosis and treatment of high density lipoprotein deficiency. Prog Cardiovasc Dis 2016;59:97-106.

29. Chen W, Lu F, Liu SJ, Du JB, Wang JM, Qian Y, Shen C, Jin GF, Hu ZB, Shen HB. Cancer risk and key components of metabolic syndrome: a population-based prospective cohort study in Chinese. Chin Med J 2012;125:481-485.

30. Madsen CM, Varbo A, Tybjærg-Hansen A, Frikke-Schmidt R, Nordestgaard BG. Ushaped relationship of $\mathrm{HDL}$ and risk of infectious disease: two prospective population-based cohort studies. Eur Heart J 2018;39:1181-1190.

31. Catapano AL, Pirillo A, Bonacina F, Norata GD. HDL in innate and adaptive immunity. Cardiovasc Res 2014;103:372-383.

32. Otocka-Kmiecik A, Mikhailidis DP, Nicholls SJ, Davidson M, Rysz J, Banach M. Dysfunctional HDL: a novel important diagnostic and therapeutic target in cardiovascular disease? Prog Lipid Res 2012;51:314-324.

33. Pirro M, Ricciuti B, Rader DJ, Catapano AL, Sahebkar A, Banach M. High density lipoprotein cholesterol and cancer: marker or causative? Prog Lipid Res 2018;71:54-69.

34. Rader DJ, deGoma EM. Approach to the patient with extremely low HDL-cholesterol. J Clin Endocrinol Metab 2012;97:3399-3407.

35. Quispe R, Al-Hiji M, Swiger KJ, Martin SS, Elshazly MB, Blaha MJ, Joshi PH, Blumenthal RS, Sniderman AD, Toth PP, Jones SR. Lipid phenotypes at the extremes of high-density lipoprotein cholesterol: the very large database of lipids-9. J Clin Lipidol 2015;9:511-518.e511-515.

36. Navab M, Anantharamaiah GM, Reddy ST, Van Lenten BJ, Fogelman AM. HDL as a biomarker, potential therapeutic target, and therapy. Diabetes 2009;58:2711-2717.

37. Su F, Kozak KR, Imaizumi S, Gao F, Amneus MW, Grijalva V, Ng C, Wagner A, Hough G, Farias-Eisner G, Anantharamaiah GM, Van Lenten BJ, Navab M, Fogelman AM, Reddy ST, Farias-Eisner R. Apolipoprotein A-I (apoA-I) and apoA-I mimetic peptides inhibit tumor development in a mouse model of ovarian cancer. Proc Natl Acad Sci U S A 2010;107:19997-20002.

38. Zamanian-Daryoush M, Lindner D, Tallant TC, Wang Z, Buffa J, Klipfell E, Parker Y, Hatala D, Parsons-Wingerter P, Rayman P, Yusufishaq MS, Fisher EA, Smith JD, Finke J, DiDonato JA, Hazen SL. The cardioprotective protein apolipoprotein A1 promotes potent anti-tumorigenic effects. J Biol Chem 2013;288:21237-21252. 
39. Gao F, Vasquez SX, Su F, Roberts S, Shah N, Grijalva V, Imaizumi S, Chattopadhyay A, Ganapathy E, Meriwether D, Johnston B, Anantharamaiah GM, Navab M, Fogelman AM, Reddy ST, Farias-Eisner R. L-5F, an apolipoprotein A-I mimetic, inhibits tumor angiogenesis by suppressing VEGF/basic FGF signaling pathways. Integr Biol 2011;3:479-489.

40. Zamanian-Daryoush M, Lindner DJ, DiDonato JA, Wagner M, Buffa J, Rayman P, Parks JS, Westerterp M, Tall AR, Hazen SL. Myeloid-specific genetic ablation of ATP-binding cassette transporter ABCA1 is protective against cancer. Oncotarget 2017;8:71965-71980.

41. Huxley RR, Barzi F, Lam TH, Czernichow S, Fang X, Welborn T, Shaw J, Ueshima H, Zimmet P, Jee SH, Patel JV, Caterson I, Perkovic V, Woodward M; Asia Pacific Cohort Studies Collaboration and the Obesity in Asia Collaboration. Isolated low levels of high-density lipoprotein cholesterol are associated with an increased risk of coronary heart disease: an individual participant data meta-analysis of 23 studies in the Asia-Pacific region. Circulation 2011;124:2056-2064.
42. Colantonio L, Fazio S, Rosenson R, Miller M, Banach M, Safford M, Muntner P, Toth P. Low high-density lipoprotein cholesterol and incident coronary heart disease among blacks in the Reasons for Geographic and Racial Differences in Stroke (REGARDS) study. J Am Coll Cardiol 2016;67:1837.

43. Rubenfire M, Brook RD. HDL cholesterol and cardiovascular outcomes: what is the evidence? Curr Cardiol Rep 2013;15:349.

44. Weissglas-Volkov D, Pajukanta P. Genetic causes of high and low serum HDL-cholesterol. J Lipid Res 2010;51:2032-2057.

45. White IR, Royston P, Wood AM. Multiple imputation using chained equations: issues and guidance for practice. Stat Med 2011;30:377-399.

46. Tsai LY, Tsai SM, Lee SC, Liu SF. Falsely low LDL-cholesterol concentrations and artifactual undetectable HDL-cholesterol measured by direct methods in a patient with monoclonal paraprotein. Clin Chim Acta 2005;358:192-195. 